\title{
Ultraestrutura celular e expressão de proteínas de leveduras hanseniaspora sob efeito do estresse etanólico
}

\author{
Cell ultrastructure and protein expression of hanseniaspora yeasts under the effect of \\ ethanol stress
}

\author{
Flavia Martins ${ }^{1}$, Maria Eugênia de Oliveira Mamede ${ }^{1 *}$, Antônio Ferreira da Silva², Jéssica Guerreiro², \\ Suzana Telles da Cunha Lima ${ }^{3}$ \\ 'Universidade Federal da Bahia (UFBA), Faculdade de Farmácia, Departamento de Análises Bromatológicas, Salvador/BA - Brasil \\ 2Universidade Federal da Bahia (UFBA), Instituto de Física, Salvador/BA - Brasil \\ ${ }^{3}$ Universidade Federal da Bahia (UFBA), Instituto de Biologia, Salvador/BA - Brasil
}

\section{*Corresponding Author:}

Maria Eugênia de Oliveira Mamede, Universidade Federal da Bahia (UFBA), Faculdade de Farmácia, Departamento de Análises Bromatológicas, Barão de Jeremoabo, s/n, Ondina, CEP 40170-115, Salvador/BA - Brasil, e-mail: mmamede@ufba.br

Cite as: Cell ultrastructure and protein expression of hanseniaspora yeasts under the effect of ethanol stress. Braz. J. Food Technol., v. 20, e2016065, 2017

\section{Resumo}

O objetivo deste estudo foi avaliar a resposta de Hanseniaspora opuntiae (Ho41) e H. guilliermondii (Hg43) ao estresse etanólico, observando a ultraestrutura e o perfil de expressão proteica em concentrações crescentes de etanol. A ultraestrutura foi analisada por microscopia eletrônica de varredura (MEV) e a expressão proteica, pelo perfil eletroforético (SDS-PAGE). Na análise microscópica, as cepas em meio Yeast Malt Agar sem etanol mostraram células jovens com morfologia apiculada, brotamento bilateral e polos distais côncavos. Com o início do estresse, a 3\% de etanol, as células apresentaram múltiplas cicatrizes em forma de anéis e, com 6\%, alterações na integridade da parede celular, plasmólise e ativação da autólise. $\mathrm{Na}$ análise eletroforética, observou-se, tanto para Ho41 quanto para Hg43, aumento na expressão de um peptídeo de $100 \mathrm{kDa}$, com aumento do etanol no meio, indicando ser uma proteína de choque térmico (HSP). As HSPs vêm sendo patenteadas como marcadores de organismos de interesse biotecnológico, já que as condições necessárias para obtenção de bioprodutos muitas vezes requerem cultivo sob estresse. Neste contexto, esta proteína pode ser indicada como marcador molecular para bioprospecção ou melhoramento genético de cepas não-saccharomyces mais resistentes aos processos de fermentação, na fabricação de vinhos.

Palavras-chave: Vinho; Marcadores de resistência; Ultraestrutura celular.

\section{Summary}

The aim of this study was to evaluate the responses of Hanseniaspora opuntiae (Ho 41) and H. guilliermondii (Hg 43) to ethanol stress, analyzing the ultrastructures and protein expression profiles under increasing ethanol concentrations. The ultrastructure was examined by scanning electron microscopy (SEM) and the protein expression from the electrophoretic profiles (SDS-PAGE). In the microscopic analyses, the strains cultivated in Yeast Malt Agar without ethanol showed young cells with apiculate morphology, bilateral budding and concave distal poles. At the start of stress, in the presence of $3 \%$ ethanol, the cells showed multiple scars in the form of rings, and with $6 \%$ ethanol they presented changes in cell wall integrity, plasmolysis and the activation of cell autolysis. In the electrophoretic analyses of both $\mathrm{Ho} 41$ and $\mathrm{Hg} 43$, an increase in the expression of a $100 \mathrm{kDa}$ peptide was noted with increasing ethanol in the media, indicating that this was a heat shock protein (HSP). The HSPs have been patented as markers for organisms of biotechnological interest since the conditions necessary to obtain bioproducts often require cultivation under stress. Thus this protein could be indicated as a molecular marker for the bio-prospection or genetic enhancement of non-saccharomyces strains more resistant to the fermentation process used in winemaking.

Keywords: Wine; Resistance markers; Cell ultrastructure. 


\section{Introdução}

Durante a fermentação espontânea ou natural realizada por leveduras presentes nas uvas ou nos equipamentos da adega, a predominância é da Saccharomyces cerevisiae, mas outros gêneros não-Saccharomyces exercem papel importante no início do processo fermentativo (FLEET, 2008; FUGELSANG; EDWARDS, 2007). As leveduras do gênero Hanseniaspora, mesmo não apresentando boa capacidade de produção de etanol durante a fermentação do vinho, contribuem com características sensoriais, produzindo compostos aromáticos, tais como ésteres, aldeídos e álcoois, entre outros (FLEET, 2008). Recentemente, foi observado (SANTOS et al., 2016) que a fermentação em mosto de uva conduzida por Hanseniaspora opuntiae ou Hanseniaspora guilliermondii exerce um papel importante na formação de compostos voláteis, que contribuíram para a aceitação do aroma do vinho, embora tenham um período de fermentação menor que a Saccharomyces cerevisiae.

Durante o complexo processo da fermentação etanólica, leveduras são expostas a vários tipos de estresse, como: altas concentrações de açúcar, etanol e instabilidade do $\mathrm{pH}$. Nessas condições, proteínas, ácidos nucleicos e membranas são danificados, afetando o crescimento, a viabilidade celular e o desempenho fermentativo da levedura. Como forma de proteção, respondem, assim como outros organismos, através do aumento na síntese de moléculas que irão reparar os danos celulares. Dentre estas, estão as proteínas de choque térmico ou Heat Shock Proteins (HSPs) (ZHANG et al., 2009; TESNIERE et al., 2013). Estas proteínas vêm sendo indicadas como marcadores de interesse biotecnológico em diversas áreas, como: sinalizadores de câncer ovariano (AHN GOOK PHARMACEUTICAL, 2014), indicadores de porcos com maior quantidade de gordura (ANIMAL TECHNOLOGY INSTITUTE OF TAIWAN, 2008) e de microalgas com maior capacidade de produção de pigmentos (UNIVERSIDADE FEDERAL DA BAHIA, 2015). Marcadores moleculares são genes ou proteínas que podem ser facilmente rastreados e quantificados em uma população, e estão associados a uma característica de interesse (HAYWARD et al., 2015). Apesar de o perfil de expressão de HSPs de diferentes leveduras já ser conhecido, estas ainda não foram utilizadas como marcadores de cepas mais resistentes ao processo fermentativo e nem no melhoramento genético de espécies não-saccharomyces.

Conhecendo-se a contribuição da Hanseniaspora para a composição do aroma do vinho, o objetivo deste estudo foi verificar alterações na ultraestrutura e na expressão proteica em Hanseniaspora opuntiae e Hanseniaspora guilliermondii durante o estresse etanólico, além de indicar possíveis proteínas marcadoras em gêneros não saccharomyces com maior resistência ao processo fermentativo.

\section{Material e métodos}

\subsection{Cepas de leveduras}

A Hanseniaspora opuntiae (Ho41) e a Hanseniaspora guilliermondii (Hg43) foram obtidas a partir de uvas cultivadas no município de Lagoa Grande-PE, Brasil, latitude 859'47" e longitude 40¹6'18", isoladas usando o método de Assis et al. (2012). Amostras de uvas foram homogeneizadas em stomacher Mc 1204 (Digital blender ITR) a 200 rpm por 2 min. Foi retirada uma alíquota de 0,1 mL e semeada com auxílio da alça de Drigalski em placas de Petri, em duplicata, contendo ágar extrato de malte-extrato de levedura (YM) (1\% de glicose (Vetec); $2 \%$ de ágar bacteriológico (Acumedia); 0,5\% de peptona (Acumedia); 0,3\% de extrato de malte (Acumedia), e 0,3\% de extrato de levedura (Acumedia), suplementadas com cloranfenicol (Himedia), na concentração 100 mg/L. As placas foram incubadas invertidas em estufa BOD (Alfakit) à temperatura de $28^{\circ} \mathrm{C}$ por $48 \mathrm{~h}$. Uma em cada oito colônias de leveduras representativas de cada amostra foi selecionada ao acaso. A identificação molecular foi realizada pelo sequenciamento da região D1/D2 da subunidade ribossomal 26S, seguindo a metodologia de Kurtzman et al. (2011).

\subsection{Condições de estresse}

Ao meio YMA (Yeast Malt Agar) (1\% glicose, 2\% ágar, 0,5\% peptona, 0,3\% extrato de malte e 0,3\% extrato de levedura), foi adicionado álcool etílico absoluto PA 99,5\% (Anidro), nas proporções 2\% 3\% e 6\% v/v, sendo as leveduras repicadas. Um meio sem etanol foi utilizado como controle. Todas as placas após semeadura foram vedadas com filmes plásticos e incubadas a $25^{\circ} \mathrm{C}$ (REIS, 2011).

\subsection{Microscopia Eletrônica de Varredura (MEV)}

Amostras secas foram montadas em suporte usando fita dupla face de carbono e, por pulverização catódica, revestidas com ouro, usando um Emitech K575X unidade de revestimento sputter (Quorum Technologies Ltd, Ashford, United Kingdom). A imagem é obtida por MEV com microscópio JEOL JSM-6610LV.

\subsection{Lise celular}

Um grama de células da colônia crescida em meio sólido (acrescido ou não de etanol) foi transferido para tubos contendo $4 \mathrm{~mL}$ de tampão fosfato $100 \mathrm{mM}$ e $5 \mathrm{mM}$ de ácido etilenodiamino tetra-acético (EDTA). Adicionaram-se $40 \mu \mathrm{L}$ de fluoreto de fenil-metano-sulfonil (PMSF) $100 \mathrm{mM}$ e as células foram ressuspensas com auxílio de um vórtice e homogeneizadas em Sonicador Bandelin UW2200 por três vezes (5 min cada). O lisado obtido foi centrifugado por $10 \mathrm{~min}$ a $10.000 \mathrm{rpm} \mathrm{e} 4^{\circ} \mathrm{C}$, sendo o precipitado 
Ultraestrutura celular e expressão de proteínas de leveduras hanseniaspora sob efeito do estresse etanólico

Martins, F. et al.

descartado e o sobrenadante colocado em gelo para caracterizações proteicas (FLEURI; SATO, 2008).

\subsection{Quantificação de proteínas - curva de BSA}

A quantificação foi feita pelo método de Bradford (1976), com curva padrão (zero a $1 \mathrm{mg} / \mathrm{mL}$ ) de soro albumina bovina (BSA). As leituras de absorbâncias foram obtidas em espectrofotômetro (SHIMADZU) a $595 \mathrm{~nm}$ e as concentrações proteicas $(\mu \mathrm{g} / \mathrm{ml})$ foram calculadas em GraphPad Prism.

\subsection{Eletroforese em gel}

Os géis de eletroforese em poliacrilamida (SDS_PAGE) foram realizados em cuba Mini Protean Tetra Cell (BIORAD). Foram aplicados $4 \mu \mathrm{g}$ de proteína e $5 \mu \mathrm{L}$ do marcador de peso molecular Bench Mark Protein Ladder. A corrida foi a 75 volts e os géis foram corados com nitrato de prata (MORTZ et al., 2001).

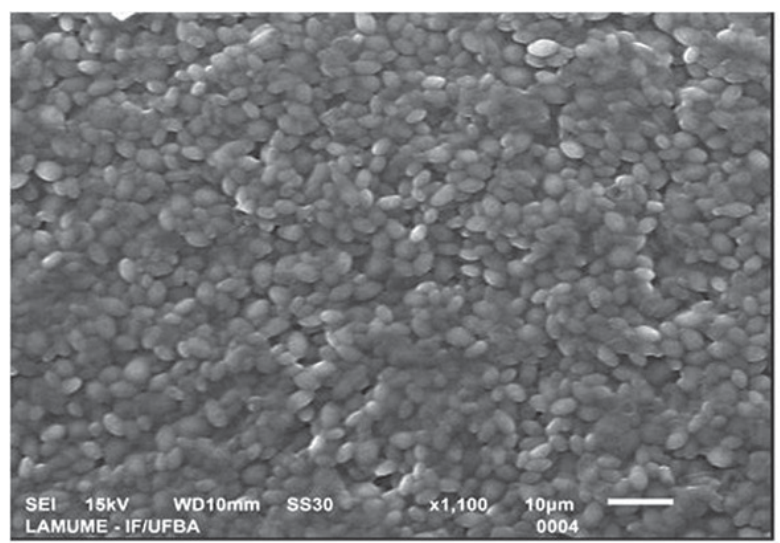

A

\section{Resultados e discussão}

\subsection{Ultraestrutura e resposta ao estresse etanólico em Hanseniaspora}

As Figura 1A e 1B mostram a morfologia de Ho41 e Hg43 em condições controle, sem adição de etanol, quando predominam células ovais e apiculadas, com brotamento bilateral.

Adicionando-se 3\% de etanol ao meio, as células começaram a mostrar maior adesão entre si (Figura 2A e 2B), com fusão da parede celular em alguns pontos. Além disso, apresentaram estruturas na forma de botão, com cicatrizes semelhantes a estrias nas regiões polares, como vistas em Hg43 (Figura 2B).

A formação de estrias apicais também foi observada por Deak e Beuchat (1996), em condições similares. Com $6 \%$ de etanol no meio, as Ho41 e Hg43 começaram a entrar em plasmólise, sendo que a morfologia celular se tornou alterada e a parede demonstrou superfície

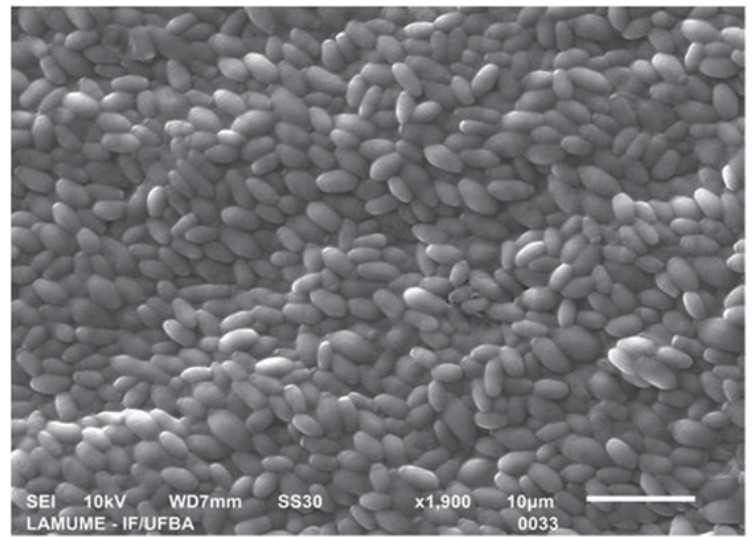

B

Figura 1. (A) H. opuntiae (Ho41) em meio YMA sem adição de etanol - Imagem aumentada 1.100x; (B) H. guillermondii (Hg43) em meio YM sem adição de etanol - Aumento 1.900x.

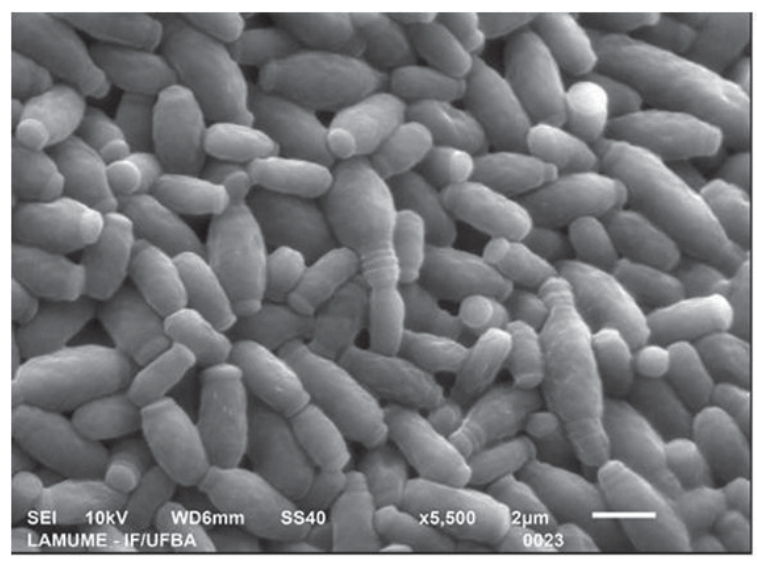

A

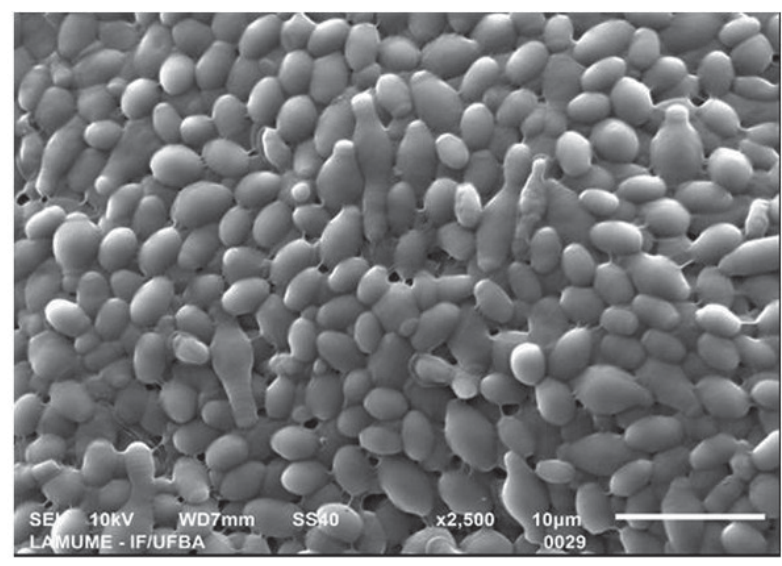

B

Figura 2. (A) H. opuntiae (Ho41) em meio YM contendo etanol (3\%) - Imagem aumentada 5.500x; (B) H. guillermondii (Hg43) em meio YMA contendo etanol (3\%) - Aumento 2.500x. 
Ultraestrutura celular e expressão de proteínas de leveduras hanseniaspora sob efeito do estresse etanólico

Martins, F. et al.

irregular (Figuras 3A e 3B). Em Hg43, na região central da célula plasmolisada, foi formada uma cavidade profunda, aparentando estar oca por dentro (Figura 3B). Apesar de esta concentração de etanol ainda ser relativamente baixa no processo fermentativo para a produção de vinho, que, normalmente, atinge 11 a $12 \%$ de etanol com Saccharomyces cerevisiae (MIELE et al., 2016), a Hanseniaspora é uma das mais resistentes dentre as leveduras não-saccharomyces (PINA et al., 2014), o que justifica a escolha deste grupo para a seleção de possíveis proteínas HSP que desempenhem o papel de marcadores moleculares.

Os perfis proteicos da Hg43 e Ho41 sob concentrações crescentes de etanol podem ser observados nas Figura 3A e 3B. Dentre as proteínas observadas, um peptídeo de 100 kDa teve aumento em sua expressão, a partir 3\% de etanol no meio, nas duas cepas estudadas (Figura 4). Essa proteína começa a ser expressa com

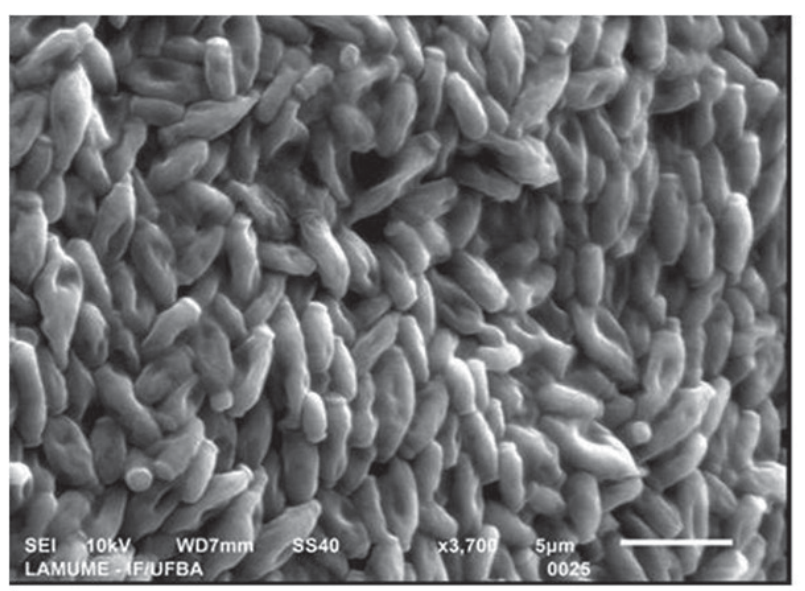

A

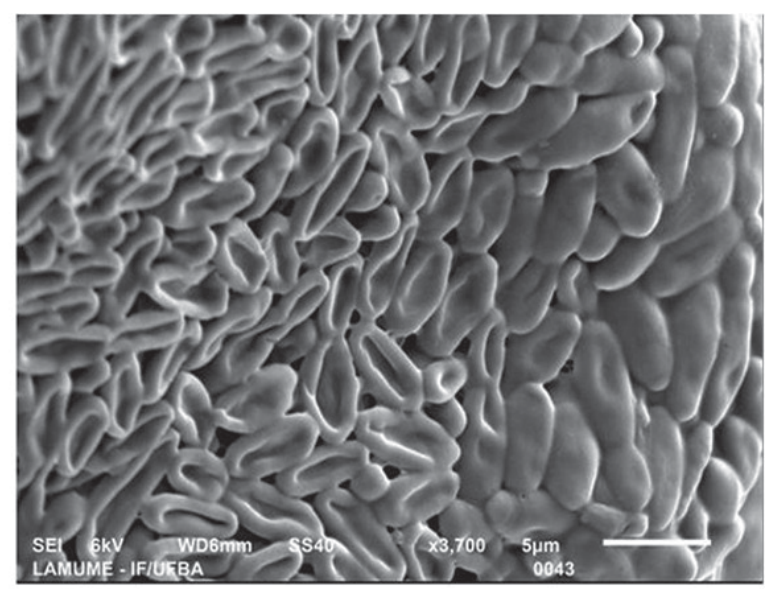

B

Figura 3. (A) H. opuntiae (Ho41) em meio YMA contendo etanol (6\%) - Aumento 3.700x; (B) H. guillermondii (Hg43) em meio YM contendo etanol (6\%) - Aumento 6.000x. Perfil proteico e marcadores de resistência.

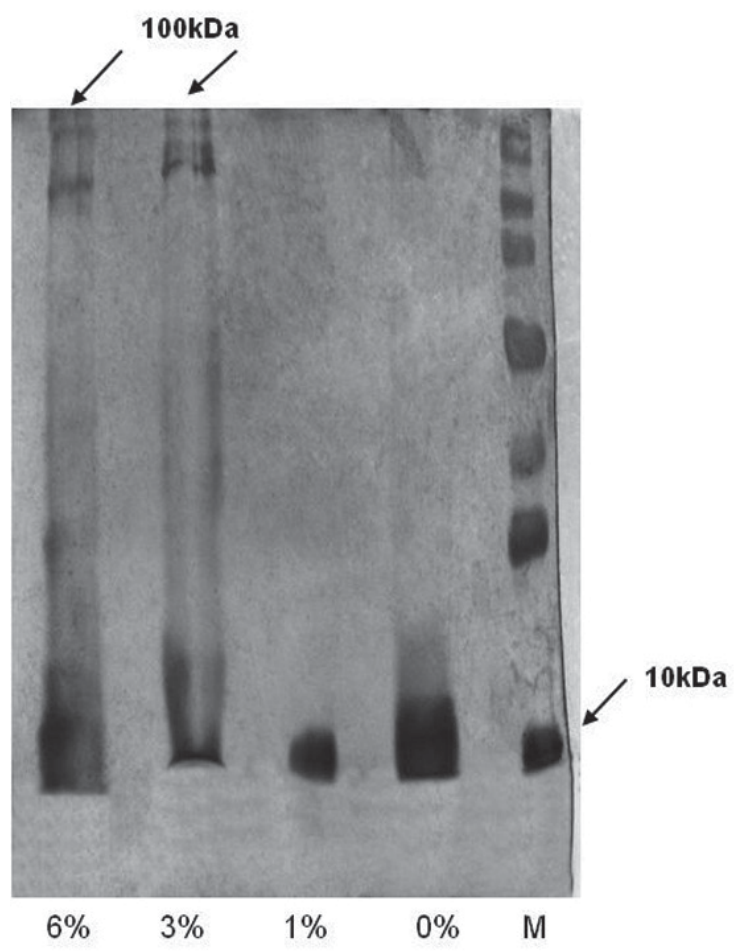

A

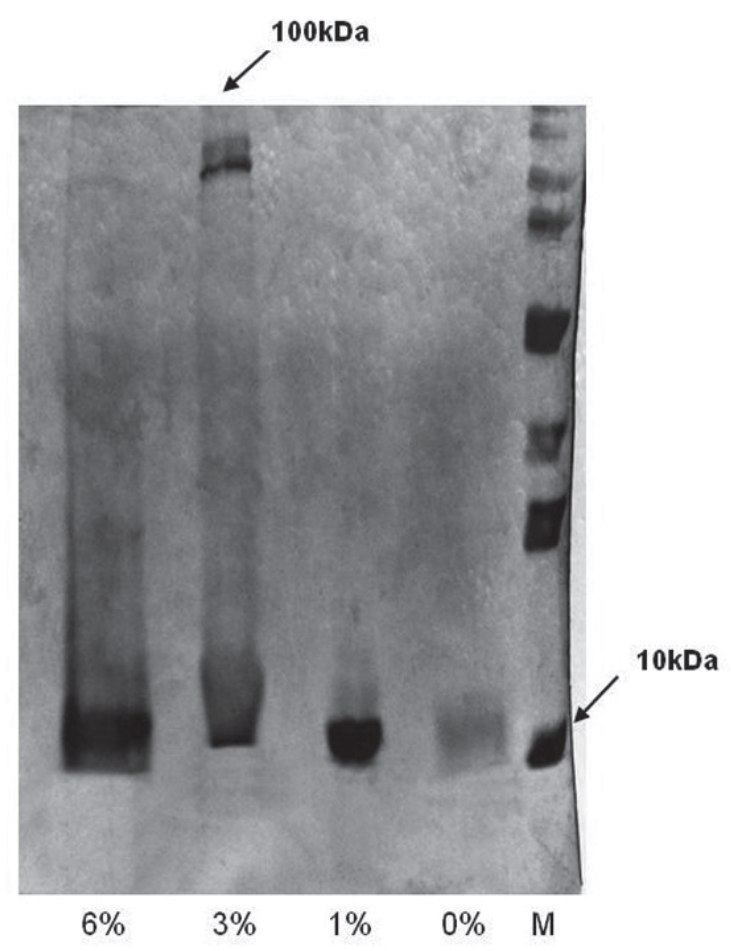

B

Figura 4. (A) H. guilliermondii (Hg43) e (B) H. opuntiae (Ho41) sob concentrações crescentes de etanol. 
$3 \%$ de etanol e, em $H$. guilliermondii ( $\mathrm{Hg} 43$ ), mantém sua expressão até $6 \%$. Um peptídeo de 10 kDa também é observado, mas está presente mesmo na ausência de etanol, não podendo ser considerado um indicador de resistência. Apesar de as condições de cultivo neste estudo serem diferentes daquelas que ocorrem durante o processo fermentativo, o crescimento em meio sólido já demonstrou ter sido eficiente para mimetizar modificações estruturais e de expressão proteica em Saccharomyces tipo selvagem e mutantes (KUBOTA et al., 2004).

Uma HSP com a mesma massa molecular já foi detectada em cepa comercial de Saccharomyces cerevisiae (SIQUEIRA-JUNIOR et al., 2015), que aumentou sua expressão durante a fermentação alcoólica, somada a outras duas de 30 e 50 kDa. Possivelmente, essas HSPs adicionais são necessárias para conferir a resistência deste gênero a concentrações bem maiores (12-15\%) de etanol no meio.

\section{Conclusão}

O crescimento de Hanseniaspora opuntiae (Ho41) e H. guilliermondii (Hg43) ocorreu no meio contendo até $6 \%$ de etanol; após esta concentração, as células ficaram aderidas umas às outras, tiveram alterações na parede celular, tornando-se irregulares, e entraram em plasmólise. Estas alterações morfológicas refletem a ausência de mecanismos moleculares de proteção, acima de 6\% de etanol. Apesar de esta concentração ainda ser baixa em processos fermentativos, este gênero é um dos mais resistentes dentre as não-saccharomyces. Esta resistência possivelmente é conferida por uma proteína de 100 kDa, a qual aumentou sua expressão a partir de 3\% de etanol no meio, indicando ser uma proteína de choque térmico.

Uma vez confirmada a identidade, esta HSPs100 poderia ser usada para melhoramento genético, induzindo a superexpressão de genes de resistência ao etanol em espécies não-saccharomyces ou ainda como marcador molecular de leveduras deste grupo, mais resistentes ao processo fermentativo. A seleção poderia ser feita através de uma triagem pelo imunoensaio western blot, usando anticorpos anti-HSP, disponíveis comercialmente. As cepas que sinalizassem presença do marcador teriam maiores chances de resistir ao processo fermentativo e de contribuir para a qualidade do aroma do vinho.

\section{Referências}

AHN GOOK PHARMACEUTICAL (Seoul, Korea). Mansfield Brian, Yip Ping, Amonkar Suraj, Bertenshaw Greg. Predictive markers for ovarian cancer. KR n. 8665348, 30 jun. 2008, 4 mar. 2014. ANIMAL TECHNOLOGY INSTITUTE OF TAIWAN (Chuanan Miaoli, Taiwan). En-Chung Lin, Ming-Yu Chen, San-Yuan Huang, Hui-Liang Tsou, Wen-Chuan Lee. Genetic markers for pig backfat thickness. US n. 20005112648, 5 out. 2004, 14 out. 2008.
ASSIS, M. O.; MAMEDE, M. E. O.; GUIMARÃES, A. G.; SANTOS, L. S.; ROSA, A. A. Yeasts isolated from Vitis vinifera L. grapes cultivated in Brazilian Equatorial Region. Revista do Instituto Adolfo Lutz, São Paulo, v. 71 n. 4, p. 718-722, 2012.

BRADFORD, M. M. A rapid and sensitive method for the quantitation of microgram quantities of protein utilizing the principle of protein-dye binding. Analytical Biochemistry, Orlando, v. 72, n. 1-2, p. 248-254, 1976. PMid:942051. http:// dx.doi.org/10.1016/0003-2697(76)90527-3.

\section{DEAK, T.; BEUCHAT, L. R. Handbook of food spoilage yeasts.} Boca Raton: CRC Press, 1996. 352 p.

FLEET, G. H. The microorganisms of winemaking-isolation enumeration and identification. In: FLEET, G. H. (Ed.). Wine microbiology and biotechnology. Chur, Switzerland: Harwood Academic Publishers, 2008. 510 p.

FLEURI, L. F.; SATO, H. H. Glucanases and chitinases: application in the yeast cell lysis and fungi inhibition. Ciência e Agrotecnologia, Lavras, v. 32, n. 4, p. 1224-1231, 2008.

FUGELSANG, K. C.; EDWARDS, C. G. Wine microbiology: practical applications and procedures. 2. ed. Fresno: Springer, 2007. 408 p.

HAYWARD, A. C.; TOLLENAERE, R.; DALTON-MORGAN, J.; BATLEY, J. Molecular marker applications in plants. Methods in Molecular Biology, Totowa, v. 1245, p. 13-27, 2015. PMid:25373746. http:// dx.doi.org/10.1007/978-1-4939-1966-6_2.

KUBOTA, S.; TAKEO, I.; KUME, K.; KANAI, M.; SHITAMUKAI, A.; MIZUNUMA, M.; MIYAKAWA, T.; SHIMOI, H.; IEFUJI, H.; HIRATA, $D$. Effect of ethanol on cell growth of budding yeast: genes that are important for cell growth in the presence of ethanol. Bioscience, Biotechnology, and Biochemistry, Abingdon, v. 68, n. 4, p. 968-972, 2004. PMid:15118337. http://dx.doi. org/10.1271/bbb.68.968.

KURTZMAN, C. P.; FELL, J. W.; BOEKHOUT, J. The yeasts, a taxonomic study. 4th ed. Amsterdam: Elsevier, 2011. 1873 p.

MIELE, A.; RIZZON, L. A.; QUEIROZ, S. C. N. A survey on the composition of wines made with grapes produced by an organic system. Brazilian Journal of Food Technology, Campinas, v. 19, p. 2015-2031, 2016. http://dx.doi.org/10.1590/1981-6723.3115.

MORTZ, E.; KROGH, T. N.; VORUM, H.; GÖRG, A. Improved silver staining protocols for high sensitivity protein identification using matrix assisted laser desorption ionization time of flight analysis. Proteomics, Weinheim, v. 1, n. 11, p. 1359-1363, 2001. PMid:11922595. http://dx.doi.org/10.1002/1615-9861(200111)1:11<1359::AIDPROT1359>3.0.CO;2-Q.

PINA, C.; SANTOS, C.; COUTO, J. A.; HOGG, T. Ethanol tolerance of five non-Saccharomyces wine yeasts in comparison with a strain of Saccharomyces cerevisiae - influence of different culture conditions. Food Microbiology, Amsterdam, v. 21, n. 4, p. 439-447, 2014. 
Ultraestrutura celular e expressão de proteínas de leveduras hanseniaspora sob efeito do estresse etanólico

Martins, F. et al.

REIS, V. R. Caracterização de linhagens selvagens de Saccharomyces cerevisiae isoladas de processos fermentativos para produção de etanol. 2011. 81 f. Dissertação (Mestrado em Ciências)-Escola Superior de Agricultura "Luiz de Queiroz", Universidade de São Paulo, Piracicaba, 2011. http://dx.doi. org/10.11606/D.11.2011.tde-18102011-160541.

SANTOS, A. P. C.; VANDERLINDE, R.; MACHADO, B. A. S.; MAMEDE, M. E. O. Improving production of aromatic compounds by indigenous yeasts in chenin blanc grape must. African Journal of Agricultural Research, Kenya, v. 11, n. 28, p. 2433-2442, 2016. http://dx.doi.org/10.5897/AJAR2016.10964.

SIQUEIRA JUNIOR, E. F.; CARVALHO FILHO, C. D.; SILVA, A. F.; LIMA, S. T. C. Searching resistance markers in Saccharomyces sp. under ethanol stress by protein profiling and ultrastructure analysis. In: WORKSHOP DE PESQUISA TECNOLOGIA E INOVAÇÃO, 5.; SIMPÓSIO INTERNACIONAL DE INOVAÇÃO E
TECNOLOGIA, 1., 2015. Salvador. Anuário... Salvador: Editora SENAI CIMATEC, 2015. v. 5. p. 276-292.

TESNIERE, C.; DELOBEL, P.; PRADAL, M.; BLONDIN, B. Impact of nutrient imbalance on wine alcoholic fermentations: nitrogen excess enhances yeast cell death in lipid-limited must. PLoS One, San Francisco, v. 8, n. 4, p. 1-11, 2013. PMid:23658613. http://dx.doi.org/10.1371/journal.pone.0061645.

UNIVERSIDADE FEDERAL DA BAHIA (Bahia, Brasil). Suzana Telles da Cunha Lima, Cíntia Jesus Almeida, Emerson Andrade Sales. Marcadores moleculares de microalgas com maior potencial de produção de betacarotenos e de outros biocompostos. BR n. 1020150131720, 19 maio 2015.

ZHANG, Q.; ZHAO, X.; JIANQ, R.; LI, Q.; BAI, F. Ethanol tolerance in yeast: molecular mechanisms and genetic engineering. Chinese Journal of Biotechnology, Beijing, v. 25, n. 4, p. 481-487, 2009. PMID: 19637619. 